\title{
Surgical anterior ventricular endocardial restoration performed with total arterial revascularization: Serial 5-year follow-up
}

\author{
Ho Young Hwang, MD, PhD, ${ }^{\mathrm{a}}$ Jun Sung Kim, MD, ${ }^{\mathrm{b}}$ Kwang Ree Cho, MD, PhD, ${ }^{\mathrm{c}}$ and Ki-Bong Kim, MD, PhD
}

Objective: We evaluated the changes in left ventricular (LV) function and volumes after surgical anterior ventricular endocardial restoration.

\begin{abstract}
Methods: A total of 63 patients who had undergone surgical anterior ventricular endocardial restoration and total arterial revascularization were included. Echocardiography and myocardial single photon emission computed tomography were performed to examine LV function and volumes preoperatively, early postoperatively, and annually thereafter to 5 years after surgery. Coronary angiography was performed at 5 years postoperatively.

Results: Operative mortality was 7.9\% (5 of 63). Echocardiograms performed before discharge demonstrated a significantly improved LV ejection fraction that was maintained at 5 years, significantly decreased early postoperative LV end-diastolic and end-systolic volume indexes that were slightly increased at 1 year and then maintained at 5 years, and early postoperative decrement of the stroke volume index that had disappeared at 1 year and had not reappeared by 5 years. Postoperative myocardial single photon emission computed tomography showed an LV ejection fraction that had gradually improved until 2 years and was maintained at 5 years, significantly decreased LV end-diastolic and end-systolic volume indexes that were maintained at 5 years, and a stroke volume index that was unchanged until 2 years and slightly increased at 3 to 4 years. The arterial graft patency rate in the left coronary territory was $95.7 \%$ (67 of 70$)$ at 5 years. The 10 -year overall survival and adverse event-free rate were $59.2 \%$ and $61.2 \%$, respectively.
\end{abstract}

Conclusions: Improved LV ejection fraction and reduced volume indexes were maintained and the stroke volume index had not decreased at 5 years after the procedure. Preserved patency of the arterial grafts might have an important role in maintaining improved LV function. (J Thorac Cardiovasc Surg 2014;148:529-35)

Surgical anterior ventricular endocardial restoration (SAVER), initially described by Dor and associates ${ }^{1}$ as endoventricular circular patch plasty, has been a surgical treatment option for the failing ischemic myocardium. The midterm clinical outcomes demonstrated relatively good midterm survival and a high degree of freedom from readmission for heart failure up to 5 years postoperatively in patients with advanced ischemic cardiomyopathy., Several studies using echocardiography, magnetic resonance imaging, and gated single photon emission computed tomography (SPECT) have demonstrated postoperative changes in left ventricular (LV) function. ${ }^{4-6}$ However, most of these studies were cross-sectional investigations performed at a defined point after SAVER.

\footnotetext{
From the Department of Thoracic and Cardiovascular Surgery, ${ }^{\text {a Seoul National }}$ University Hospital, Seoul, South Korea; Department of Thoracic and Cardiovascular Surgery, ${ }^{\mathrm{b}}$ Seoul National University Bundang Hospital, Gyeonggi-do, South Korea; and Department of Thoracic and Cardiovascular Surgery, ${ }^{\mathrm{c}}$ Sejong General Hospital, Gyeonggi-do, South Korea.

Disclosures: Authors have nothing to disclose with regard to commercial support.

Received for publication March 27, 2013; revisions received Sept 20, 2013; accepted

for publication Oct 13, 2013; available ahead of print Nov 26, 2013.

Address for reprints: Ki-Bong Kim, MD, PhD, Department of Thoracic and

Cardiovascular Surgery, Seoul National University Hospital, 101 Daehak-ro,

Jongno-gu, Seoul 110-744, South Korea (E-mail: kimkb@snu.ac.kr).

$0022-5223 / \$ 36.00$

Copyright (c) 2014 by The American Association for Thoracic Surgery

http://dx.doi.org/10.1016/j.jtcvs.2013.10.022
}

The aim of the present study was to demonstrate the serial changes in LV function and volume indexes using echocardiography and myocardial SPECT for $\leq 5$ years after SAVER performed concomitant with total arterial coronary artery bypass grafting (CABG).

\section{METHODS}

\section{Patient Characteristics}

The institutional review board reviewed the study protocol and approved it as a minimal-risk retrospective study (approval no. H-1201-006-392) that did not require individual patient consent according to the institutional guidelines for waiving consent.

From 1999 to 2005, 63 patients (44 men and 19 women) who had undergone SAVER with concomitant total arterial CABG were studied. The mean patient age at surgery was $62.7 \pm 9.0$ years. Hypertension $(\mathrm{n}=38,60.3 \%)$ and diabetes mellitus $(\mathrm{n}=27,42.9 \%)$ were common comorbidities (Table 1).

\section{Operative Strategy}

SAVER was performed using cardiopulmonary bypass and cold blood cardioplegic arrest $(\mathrm{n}=48,76.2 \%)$ or ventricular fibrillation $(\mathrm{n}=15,23.8 \%)$ with moderate hypothermia $\left(25^{\circ}-28^{\circ} \mathrm{C}\right)$. The mean cardiopulmonary bypass time was $153 \pm 66$ minutes, and the mean aortic crossclamp time in 48 patients was $66 \pm 25$ minutes. The left ventricle was opened parallel to the left anterior descending coronary artery. An endoventricular circular pursestring suture using a 2-0 monofilament suture was placed circumferentially in the transitional zone between the normal and diseased myocardium. A balloon was inserted into the ventricular base, and the $\mathrm{LV}$ diastolic volume was adjusted to $50-70 \mathrm{~mL} / \mathrm{m}^{2}$ by 


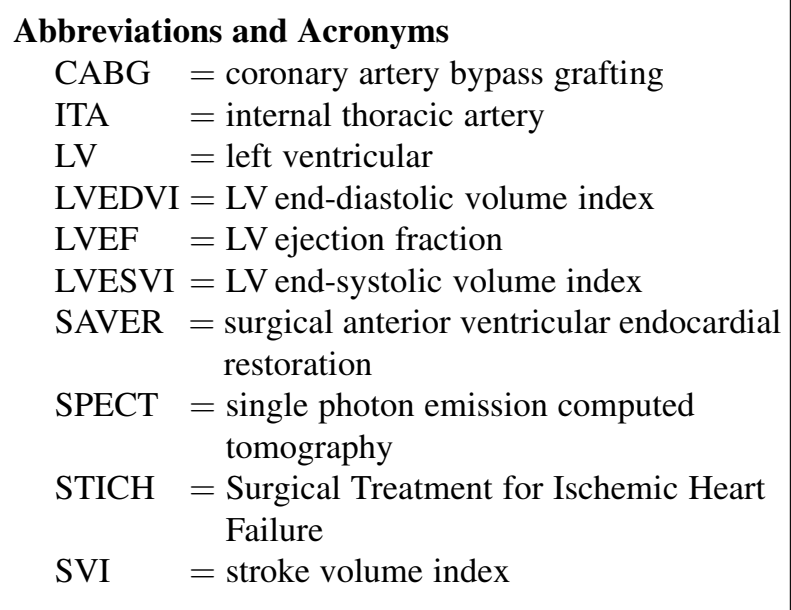

tightening the pursestring suture. A commercially available woven vascular patch, with the size determined by the circumference of the circular suture after balloon removal, was used to close the defect. Coronary revascularization was performed after SAVER, and most revascularizations were performed under an on-pump beating heart after releasing the aortic crossclamping. The left internal thoracic artery (ITA) was used in all patients. It was commonly anastomosed to the left anterior descending coronary artery territory $(\mathrm{n}=52,82.5 \%)$. The additional arterial conduits used for total arterial revascularization were the right ITA $(\mathrm{n}=38)$ and right gastroepiploic artery $(\mathrm{n}=33$; Table 2$)$. When bilateral ITAs were used as in situ grafts, the right ITA was anastomosed to the left anterior descending coronary artery $(\mathrm{n}=7,11.5 \%)$. The mean number of distal anastomoses was $2.5 \pm 0.9$. Mitral annuloplasty was performed when preoperative echocardiography revealed mitral regurgitation of moderate or greater degree $(n=11,17.5 \%)$. Partial flexible rings were inserted in all 11 patients (Duran AnCore ring, Medtronic, Inc, Minneapolis, Minn, in 6, and Cosgrove-Edwards ring, Edwards Lifesciences, Irvine, Calif, in 5). One patient underwent mitral valve replacement because of combined rheumatic mitral pathologic features.

\section{Evaluation of Clinical Outcomes}

The patients underwent regular postoperative follow-up examinations at the outpatient clinic at 3- or 4-month intervals and were interviewed by telephone for confirmation of their condition if the last clinic visit had not occurred at the scheduled time. The clinical follow-up period for all patients was completed on December 31, 2012. The follow-up data were complete for 52 of the 57 survivors $(91.2 \%)$, with a median follow-up duration of 103 months (range, 6-160). Operative mortality was defined as any death within 30 days, including death after hospital discharge. Cardiac death was defined as any death related to cardiac events, including sudden death during the follow-up period. Major adverse cardiac or cerebrovascular events included cardiac death (including sudden death during follow-up); acute myocardial infarction; heart failure needing readmission; reoperation or coronary intervention; and cerebrovascular accident.

\section{Evaluation of LV Function}

The LV ejection fraction (LVEF), LV end-diastolic and end-systolic volume index (LVEDVI and LVESVI, respectively), and stroke volume index (SVI) were measured preoperatively using transthoracic echocardiography and myocardial SPECT. For echocardiographic evaluation, the modified biplane Simpson method was used to calculate the LVEF and LV volumes. Myocardial SPECT images were obtained using dual-head gamma cameras (Vertex EPIC, ADAC Laboratories, Milpitas,
Calif). The images were reconstructed into 16 -frame gated images using a filtered back-projection technique. The LV volumes were automatically calculated using a software package (QGS, Cedars-Sinai, Los Angeles, Calif) in which an automatic myocardial border detection algorithm was implemented. ${ }^{7}$ Postoperative echocardiographic evaluations were performed before discharge and annually thereafter to 5 years. Postoperative myocardial SPECT was performed at 3 months and annually thereafter to 5 years.

\section{Angiographic Evaluation of Graft Patency}

Early (10 \pm 13 days), 1-year (12.2 \pm 1.1 months), and 5-year $(61.1 \pm 7.2$ months) follow-up coronary angiography was performed regardless of the patients' angina symptoms in $92 \%$ (58 of 63 ), $98.1 \%$ (52 of 53), and $80.5 \%$ (33 of 41) of the patients available for follow-up for each period, respectively. Graft patency was graded as described by FitzGibbon and colleagues. ${ }^{8}$ Steno-occlusion was defined as occluded or stenosis of $\geq 75 \%$ diameter. $^{8}$

\section{Statistical Analysis}

Statistical analysis was performed using the IBM SPSS, version 19 (IBM, Armonk, NY) and Statistical Analysis Systems, version 9.1 (SAS Institute, Cary, NC), software packages. Data are presented as mean \pm standard deviation, median and range, or proportions. $P<.05$ was considered statistically significant. Angiographic patency rates were compared using a generalized estimating equation. Serial changes in LVEF, LVEDVI, LVESVI, and SVI were also analyzed using generalized estimating equations. All pairwise comparisons on time were performed using the Sidak method. Survival rates were estimated using the Kaplan-Meier method.

\section{RESULTS \\ Clinical Outcomes}

The operative mortality was $7.9 \%$ (5 of 63 patients). The postoperative complications included atrial fibrillation $(\mathrm{n}=17,27.0 \%)$, low cardiac output syndrome $(\mathrm{n}=13$, $7.9 \%)$, reoperation for bleeding $(\mathrm{n}=8,12.7 \%)$, acute renal failure $(\mathrm{n}=5,7.9 \%)$, perioperative myocardial infarction $(\mathrm{n}=5,7.9 \%)$, and mediastinitis $(\mathrm{n}=1,1.6 \%)$. Late deaths during the follow-up period occurred in 19 patients, including 8 cardiac deaths. The 5- and 10-year overall survival rates were $72.4 \%$ and $59.2 \%$, respectively. During the follow-up period, 5 patients underwent percutaneous coronary intervention because of progression of native coronary artery disease in 3 patients and occlusion of the right gastroepiploic artery conduit anastomosed to the posterior descending coronary artery in 2 patients. None of patients underwent redo-CABG. Eight patients required readmission for management of aggravated congestive heart failure. Another 3 patients experienced cerebrovascular events during the follow-up period. The 5- and 10-year freedom from major adverse cardiac or cerebrovascular event rates were $73.8 \%$ and $61.2 \%$, respectively (Figure 1).

\section{Echocardiographic Results}

The serial echocardiographic examinations demonstrated that the LVEF had improved significantly early after surgery (preoperative vs early postoperative, 
TABLE 1. Preoperative characteristics and risk factors $(n=63)$

\begin{tabular}{lc}
\hline \multicolumn{1}{c}{ Variable } & Value \\
\hline Age $(\mathrm{y})$ & $62.7 \pm 9.0$ \\
Gender & \\
Male & 44 \\
Female & 19 \\
Risk factor & \\
Smoking & $29(46.0)$ \\
Hypertension & $38(60.3)$ \\
Diabetes mellitus & $27(42.9)$ \\
Dyslipidemia & $15(23.8)$ \\
History of stroke & $7(11.1)$ \\
Chronic renal failure & $6(9.5)$ \\
Diagnosis & \\
Left main disease & $8(12.7)$ \\
Three-vessel disease & $37(58.7)$ \\
\hline Data presented as mean \pm standard deviation or $\mathrm{n}(\%)$. &
\end{tabular}

Data presented as mean \pm standard deviation or $\mathrm{n}(\%)$.

$32.4 \% \pm 9.0 \%$ vs $37.5 \% \pm 10.3 \% ; P<.001)$. Although the LVEF had improved further at 4 and 5 years after surgery, the difference was not statistically significant compared with the early postoperative value. The early postoperative LVEDVI and LVESVI had decreased significantly. Both volume indexes were slightly increased at 1 year postoperatively compared with the early postoperative values and were then maintained for 5 years. Early postoperative SVI decreased significantly; however, the decrement had disappeared at 1 year and had not reappeared by 5 years (Table 3 and Figure 2).

None of the 11 patients who had undergone concomitant posterior mitral annuloplasty demonstrated residual mitral regurgitation of moderate or greater degree early after surgery. Follow-up echocardiography was performed in 9 patients at a median of 51 months (range, 6-123) after surgery, and recurrent mitral regurgitation of moderate or greater degree was found in only 1 patient.

\section{Myocardial SPECT Results}

The results of myocardial SPECT were similar to those of echocardiography. Serial myocardial SPECT demonstrated that the LVEF had improved significantly at 3 months postoperatively (preoperative vs 3 months, $26.6 \% \pm 8.4 \%$ vs $36.3 \% \pm 11.3 \%, P<.001)$ and had improved further at 2 years postoperatively ( 3 months vs 2 years, $36.3 \% \pm$ $11.3 \%$ vs $41.0 \% \pm 10.6 \%, P=.008)$. The changes in LVEF $>2$ years postoperatively were not statistically

TABLE 2. Arterial grafts used in coronary artery bypass grafting

\begin{tabular}{lcccc}
\hline Graft & In situ & Composite & Free & Total \\
\hline Left ITA & 62 & 1 & 0 & $63(100)$ \\
Right ITA & 7 & 31 & 0 & $38(60.3)$ \\
RGEA & 17 & 15 & 1 & $33(52.4)$ \\
\hline
\end{tabular}

Data presented as $\mathrm{n}(\%) . I T A$, Internal thoracic artery; RGEA, right gastroepiploic artery.
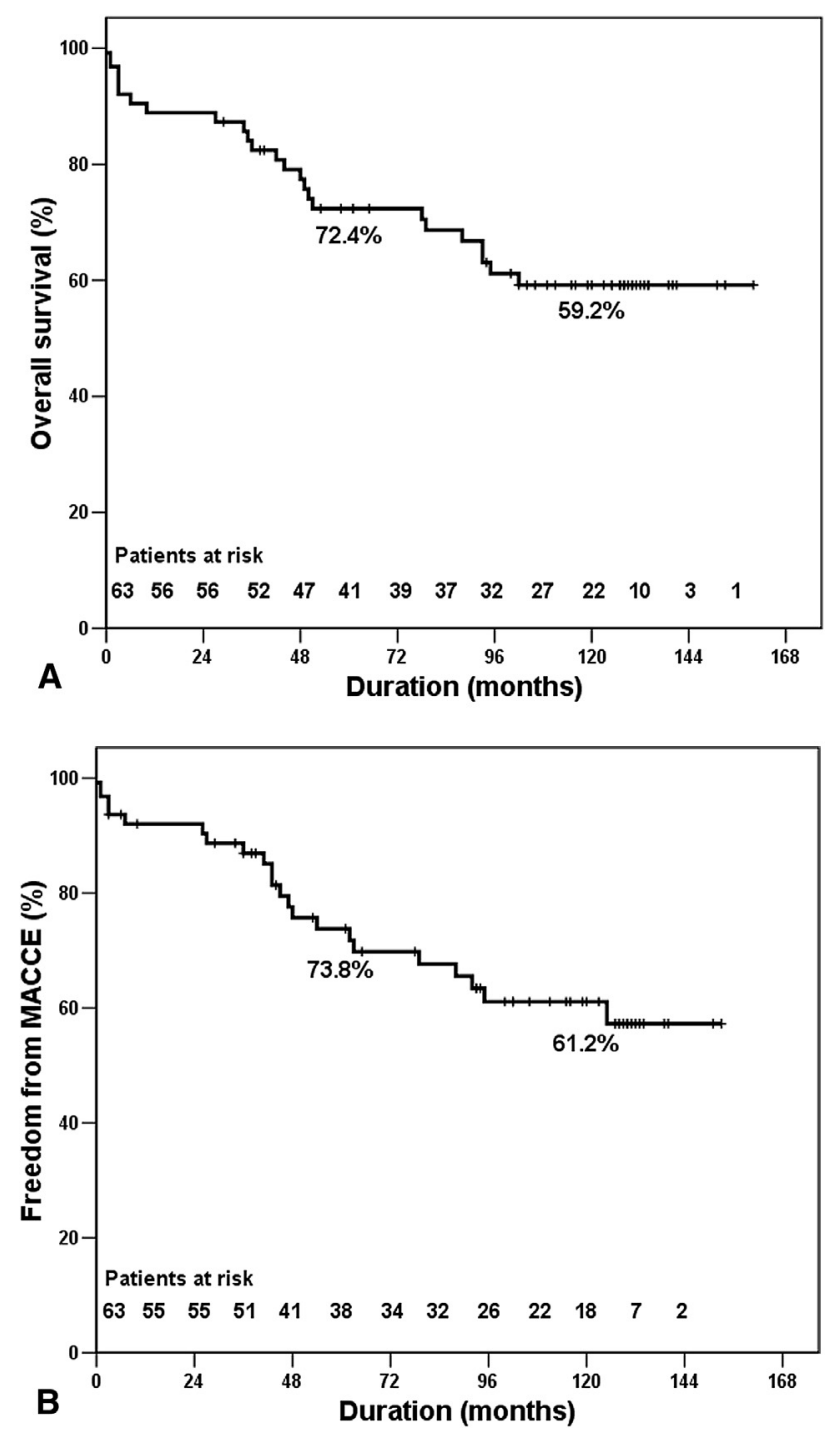

FIGURE 1. Kaplan-Meier curves of (A) overall survival and (B) freedom from major adverse cardiac or cerebrovascular events. The 5and 10-year overall survival and freedom from major adverse cardiac or cerebrovascular event rates were $72.4 \%$ and $59.2 \%$, and $73.8 \%$ and $61.2 \%$, respectively.

significant compared with the LVEF at 2 years. The LVEDVI and LVESVI had both decreased significantly at 3 months postoperatively (LVEDVI, $129.5 \pm 42.4$ vs 93.4 $\pm 31.1 \mathrm{~mL} / \mathrm{m}^{2}, P<.001 ;$ LVESVI, $97.2 \pm 40.4$ vs $61.4 \pm$ $\left.27.9 \mathrm{~mL} / \mathrm{m}^{2}, P<.001\right)$. After 3 months, no statistically significant changes were found in the LVEDVI and LVESVI during the 5 postoperative years. The SVI did not change until 2 years postoperatively and had increased slightly at 3 to 4 years (Table 4 and Figure 3).

\section{Angiographic Patency Rates}

The overall graft patency rates at early, 1 year, and 5 years postoperatively were $99.3 \%$ (148 of 149 ), 
TABLE 3. Changes in left ventricular function and volumes after surgical anterior ventricular endocardial restoration with concomitant total arterial revascularization measured using transthoracic echocardiography

\begin{tabular}{|c|c|c|c|c|c|c|c|}
\hline \multirow[b]{2}{*}{ Variable } & \multirow[b]{2}{*}{ Preoperative data $(n=58)$} & \multicolumn{6}{|c|}{ Postoperative data } \\
\hline & & Early $(n=58)$ & $1 y(n=53)$ & $2 y(n=47)$ & $3 y(n=41)$ & $4 y(n=39)$ & $5 y(n=33)$ \\
\hline $\operatorname{LVEF}(\%)$ & $32.4 \pm 9.0$ & $37.5 \pm 10.3^{*}$ & $41.0 \pm 0.7^{*}$ & $40.5 \pm 9.8^{*}$ & $40.6 \pm 9.3 *$ & $43.1 \pm 10.6^{*}$ & $44.7 \pm 11.5^{*}$ \\
\hline LVEDVI $\left(\mathrm{mL} / \mathrm{m}^{2}\right)$ & $91.1 \pm 8.6$ & $59.4 \pm 22.0^{*}$ & $75.5 \pm 24.0^{*}, \dagger$ & $75.0 \pm 23.2^{*}, \dagger$ & $78.1 \pm 21.9 \dagger$ & $74.3 \pm 19.5 \dagger$ & $74.0 \pm 21.3 \dagger$ \\
\hline LVESVI (mL/m²) & $62.5 \pm 34.3$ & $38.4 \pm 17.0^{*}$ & $45.8 \pm 21.9^{*}, \ddagger$ & $45.5 \pm 21.3^{*}$ & $47.9 \pm 20.0 \S, \|$ & $41.6 \pm 15.4^{*}$ & $42.9 \pm 17.7 \S$ \\
\hline $\mathrm{SVI}\left(\mathrm{mL} / \mathrm{m}^{2}\right)$ & $28.6 \pm 8.7$ & $21.4 \pm 9.1^{*}$ & $30.0 \pm 7.7 \dagger$ & $30.7 \pm 10.2 \dagger$ & $29.6 \pm 7.6 \dagger$ & $30.8 \pm 10.7 \pi$ & $29.1 \pm 10.9 \#$ \\
\hline
\end{tabular}

$\overline{L V E F}$, Left ventricular ejection fraction; $L V E D V I$, left ventricular end-diastolic volume index; $L V E S V I$, left ventricular end-systolic volume index; $S V I$, stroke volume index. $* P<.001$ compared with preoperative value. $\dagger P<.001$ compared with early postoperative value. $\ddagger P=.027$ compared with early postoperative value. $\S P=.004$ compared with preoperative value. $\| P=.004$ compared with early postoperative value. $₫ P=.005$ compared with early postoperative value. $\# P=.016$ compared with early postoperative value.

$97.0 \%$ (129 of 133 ), and $92.0 \%$ (81 of 88 ), respectively (Table 5). When the graft patency rates were compared according to the target coronary territories, the graft patency rates in the left coronary artery territory were significantly greater than those in the right coronary artery territory at 5 years postoperatively $(95.7 \%$

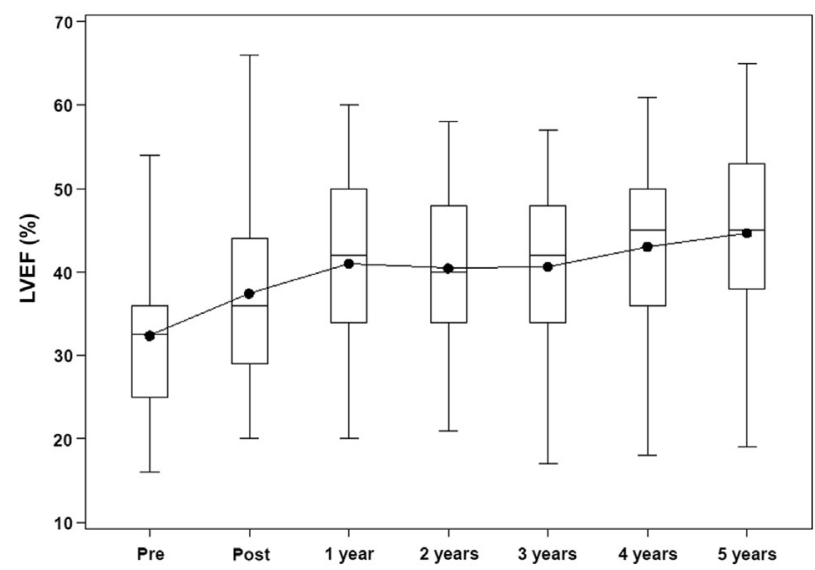

A

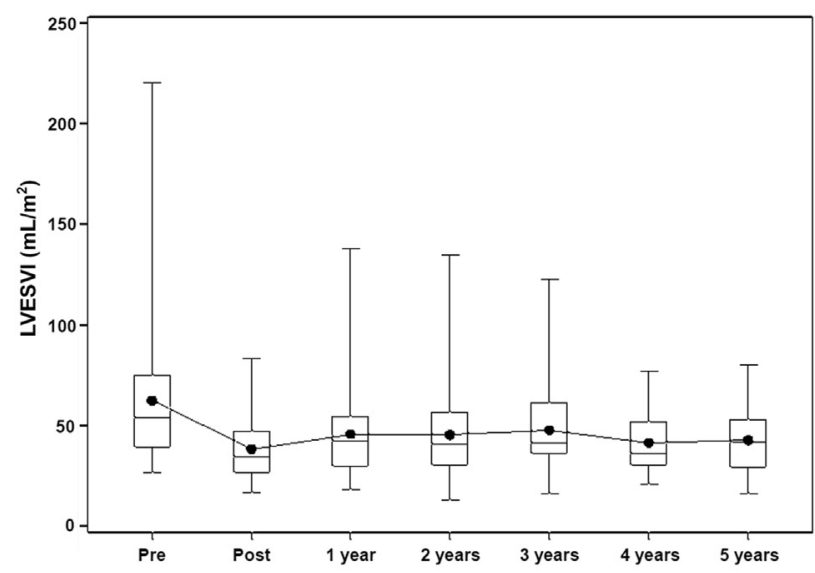

C
[67 of 70] vs $77.8 \%$ [14 of 18], $P=.026$ ). The patency rate of the right gastroepiploic artery conduit was $92 \%$ (81 of 88 ) at 5 years postoperatively and was significantly greater in the left coronary artery territory than in the right coronary artery territory $(95.7 \%$ [67 of 70$]$ vs $77.8 \%$ [14 of 18 ], $P=.03$ ).

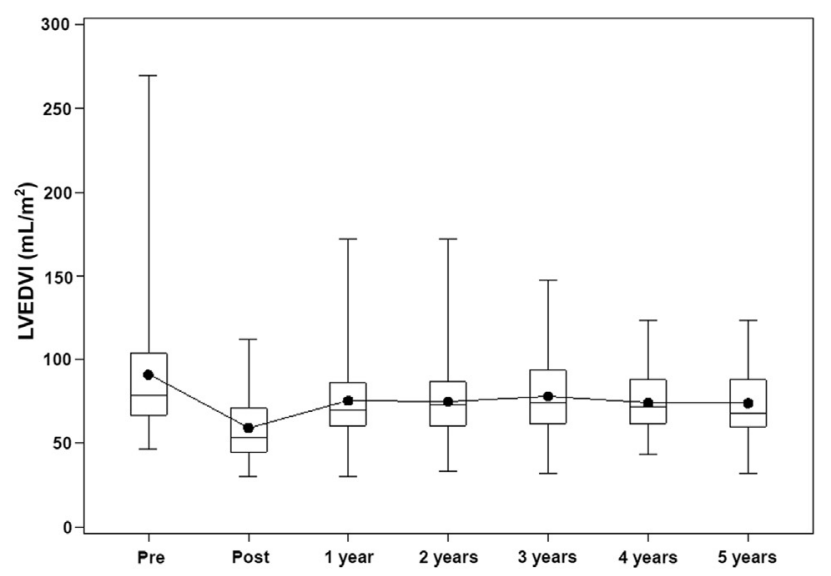

B

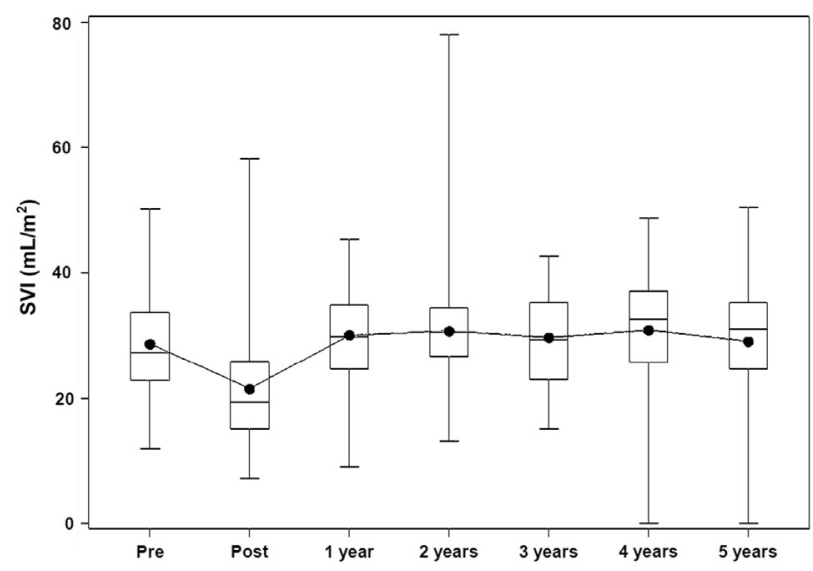

D

FIGURE 2. Changes in the (A) left ventricular ejection fraction ( $L V E F)$, (B and C) left ventricular end-diastolic and end-systolic volume indexes (LVEDVI and LVESVI), and (D) stroke volume index (SVI) before surgery (pre), early after surgery (post), and 1 to 5 years postoperatively, measured on the transthoracic echocardiograms. (The central box represents the values from the lower to upper quartile and the middle line, the median; a line extends from the minimum to the maximum value.) 
TABLE 4. Changes in left ventricular function and volumes after surgical anterior ventricular endocardial restoration with concomitant total arterial revascularization measured using myocardial single photon emission computed tomography

\begin{tabular}{|c|c|c|c|c|c|c|c|}
\hline \multirow[b]{2}{*}{ Variable } & \multirow[b]{2}{*}{ Preoperative data $(\mathbf{n}=\mathbf{5 7})$} & \multicolumn{6}{|c|}{ Postoperative data } \\
\hline & & $3 \mathrm{mo}(\mathrm{n}=55)$ & $1 y(n=52)$ & $2 y(n=44)$ & $3 y(n=43)$ & $4 y(n=39)$ & $5 y(n=30)$ \\
\hline $\operatorname{LVEF}(\%)$ & $26.6 \pm 8.4$ & $36.3 \pm 11.3 *$ & $39.7 \pm 12.1^{*}$ & $41.0 \pm 10.6^{*}, \dagger$ & $42.7 \pm 12.0^{*}, \ddagger$ & $43.9 \pm 10.0 *, \ddagger$ & $45.5 \pm 12.3^{*}$ \\
\hline $\operatorname{LVEDVI}\left(\mathrm{mL} / \mathrm{m}^{2}\right)$ & $129.5 \pm 42.4$ & $93.4 \pm 31.1^{*}$ & $88.6 \pm 35.5^{*}$ & $89.3 \pm 35.6^{*}$ & $94.3 \pm 36.2^{*}$ & $91.0 \pm 33.6^{*}$ & $87.4 \pm 36.1^{*}$ \\
\hline LVESVI $\left(\mathrm{mL} / \mathrm{m}^{2}\right)$ & $97.2 \pm 40.4$ & $61.4 \pm 27.9^{*}$ & $56.5 \pm 32.0^{*}$ & $55.7 \pm 31.2 *$ & $57.3 \pm 33.0^{*}$ & $53.6 \pm 28.4^{*}$ & $50.9 \pm 30.2^{*}$ \\
\hline $\operatorname{SVI}\left(\mathrm{mL} / \mathrm{m}^{2}\right)$ & $31.9 \pm 8.1$ & $32.1 \pm 7.4$ & $32.0 \pm 6.9$ & $32.8 \pm 8.6$ & $37.0 \pm 7.9 \S$ & $37.4 \pm 7.3 \|$ & $36.5 \pm 8.7$ \\
\hline
\end{tabular}

$L V E F$, Left ventricular ejection fraction; $L V E D V I$, left ventricular end-diastolic volume index; $L V E S V I$, left ventricular end-systolic volume index; $S V I$, stroke volume index. $* P<.001$ compared with preoperative value. $\dagger P=.008$ compared with 3 -month postoperative value. $\ddagger P<.001$ compared with 3 -month postoperative value. $\S P=.028$, $P=.021$, and $P=.011$ compared with preoperative, 3-month postoperative, and 1-year postoperative value, respectively. $\| P=.005, P=.001$, and $P=<.001$ compared with preoperative, 3-month postoperative, and 1-year postoperative value, respectively.

\section{DISCUSSION}

The present study has revealed 2 main findings. First, improved LV function and volume indexes were maintained for 5 years after SAVER. Second, the 5-year graft patency rate in the left coronary artery territory was $>95 \%$ after

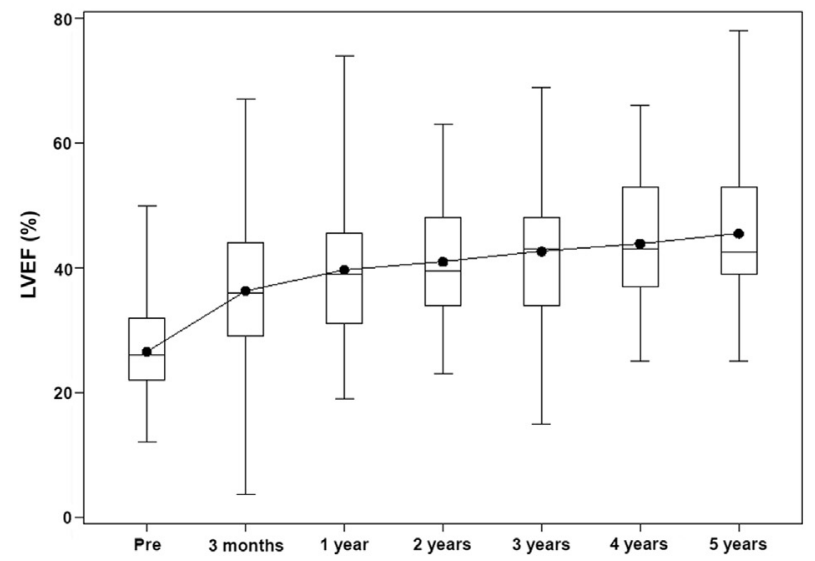

A

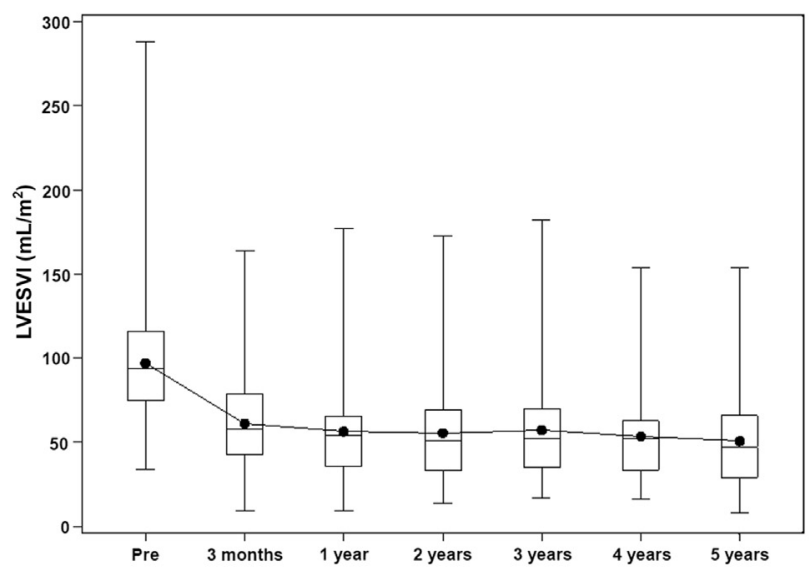

C total arterial revascularization, which might have positively affected the maintenance of the LV function and volumes after SAVER.

SAVER, initially described by Dor and associates, ${ }^{1}$ has been performed to reshape the dilated left ventricle caused

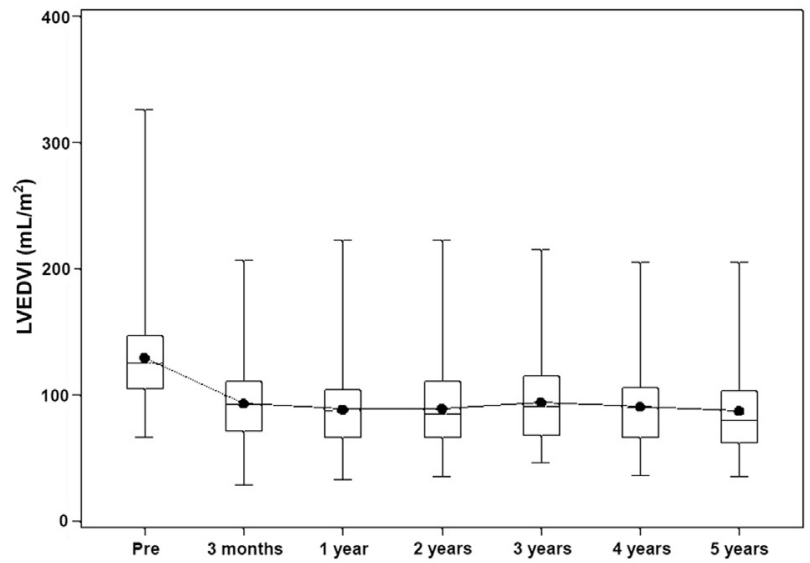

B

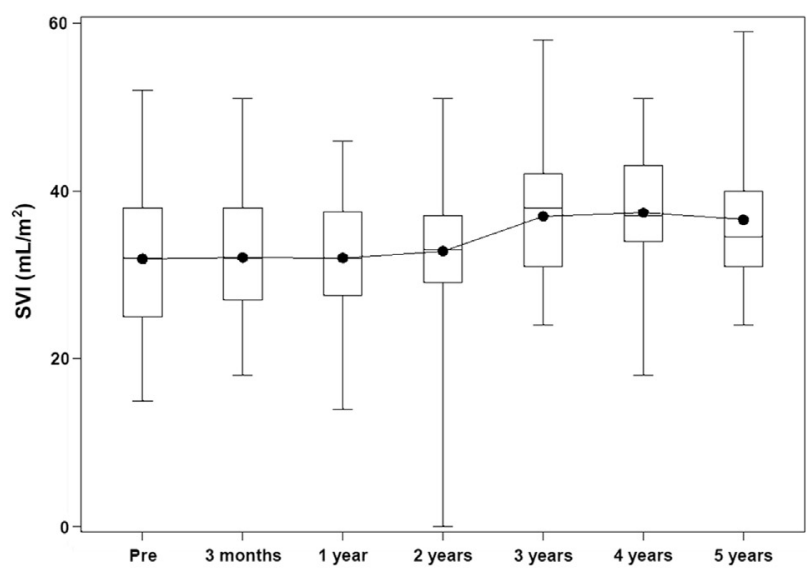

D

FIGURE 3. Changes in the (A) left ventricular ejection fraction $(L V E F)$, (B and C) left ventricular end-diastolic and end-systolic volume indexes ( $L V E D V I$ and $L V E S V I$ ), and (D) stroke volume index (SVI) before surgery (pre), 3 months after surgery, and 1 to 5 years postoperatively, measured on myocardial single photon emission computed tomography scans. (The central box represents the values from the lower to upper quartile, and the middle line, the median; a line extends from the minimum to the maximum value.) 
TABLE 5. Early, 1-year, and 5-year angiographic patency rates

\begin{tabular}{|c|c|c|c|c|c|c|}
\hline Patency & Graft & LCA & LAD & $\mathbf{L C x}$ & RCA & Total \\
\hline \multicolumn{7}{|c|}{ Early $(n=58)$} \\
\hline & LITA & $68 / 68$ & $59 / 59$ & $9 / 9$ & $0 / 0$ & $68 / 68(100)$ \\
\hline & RITA & $38 / 38$ & $14 / 14$ & $24 / 24$ & $6 / 6$ & $44 / 44(100)$ \\
\hline & RGEA & $15 / 15$ & $4 / 4$ & $11 / 11$ & $21 / 22$ & $36 / 37(97.3)$ \\
\hline & Total & $121 / 121(100)$ & & & $27 / 28(96.4)$ & $148 / 149(99.3)$ \\
\hline \multicolumn{7}{|l|}{$1 \mathrm{y}(\mathrm{n}=52)$} \\
\hline & LITA & $59 / 60$ & $50 / 51$ & $9 / 9$ & $0 / 0$ & $59 / 60(98.3)$ \\
\hline & RITA & $33 / 33$ & $13 / 13$ & $20 / 20$ & $3 / 4$ & $36 / 37(97.3)$ \\
\hline & RGEA & $14 / 15$ & $3 / 3$ & $11 / 12$ & $20 / 21$ & $34 / 36(94.4)$ \\
\hline & Total & $106 / 108(98.1)$ & & & $23 / 25(92.0)$ & $129 / 133(97.0)$ \\
\hline \multicolumn{7}{|l|}{$5 \mathrm{y}(\mathrm{n}=33)$} \\
\hline & LITA & $38 / 39$ & $31 / 32$ & $7 / 7$ & $0 / 0$ & $38 / 39(97.4)$ \\
\hline & RITA & $23 / 24$ & $10 / 10$ & $13 / 14$ & $2 / 3$ & $25 / 27$ (92.6) \\
\hline & RGEA & $6 / 7$ & $1 / 1$ & $5 / 6$ & $12 / 15$ & $18 / 22(81.8)$ \\
\hline & Total & $67 / 70(95.7)$ & & & $14 / 18(77.8)$ & $81 / 88(92.0)$ \\
\hline
\end{tabular}

Data presented as $\mathrm{n}(\%) . L C A$, Left coronary artery; $L A D$, left anterior descending artery; $L C x$, left circumflex artery; RCA, right coronary artery; $L I T A$, left internal thoracic artery; RITA, right internal thoracic artery; RGEA, right gastroepiploic artery.

by ischemic cardiomyopathy. Previous studies have demonstrated improved LVEF and reduced LV volume indexes after SAVER. ${ }^{4-6}$ However, most of these studies were cross-sectional investigations performed at a defined point after SAVER. One previous study using myocardial SPECT evaluated the midterm changes in LV function after SAVER. ${ }^{4}$ The early and midterm postoperative LV volumes and LVEF were measured in 14 patients. Decreased LVEDVI and LVESVI and improved LVEF were demonstrated early postoperatively. An additionally decreased LVESVI and improved LVEF were observed at the midterm postoperative follow-up point. Another study using echocardiography demonstrated that the reduced LV volumes early after surgery increased again at the midterm follow-up point ( $\geq 6$ months after surgery). ${ }^{9}$ They suggested that progressive LV sphericity after surgery subsequently increased wall tension and redilatation of the LV volumes. Those studies, however, included only a small number of patients and the ventricular volumes were measured at 2 postoperative periods. Another previous study, including 234 patients, demonstrated that the SVI had frequently decreased early postoperatively and had recovered at midterm follow-up after surgical ventricular restoration despite uniformly decreased LV volume indexes and improved LVEF. ${ }^{10}$ Those investigators suggested that the ventricle had regained its preload reserve, allowing the stroke volume to increase during exercise, independent of the baseline value of the stroke volume at rest, in accordance with the well-demonstrated clinical improvement after surgery. ${ }^{11}$ In the present study, we evaluated the LVEF, LV volume indexes, and SVI preoperatively, early postoperatively, and annually thereafter to 5 years postoperatively using transthoracic echocardiography and myocardial SPECT. Serial examinations of both studies demonstrated similar findings: the LVEF had improved and the LVEDVI and LVESVI had decreased postoperatively and were maintained during the 5-year study period. Our results have suggested that the LV volume was significantly reduced in the immediate postoperative period, had slightly increased during the early postoperative period, and was then maintained during the 5-year study period. Echocardiography demonstrated that the SVI had decreased early postoperatively but had recovered by 1 year, with the recovery maintained throughout the 5-year study period. However, myocardial SPECT demonstrated slightly increased SVI during postoperative years 3 to 4 .

Previous studies have demonstrated 5-year overall and heart failure-free survival rates of $68 \%$ to $82 \%$ and $58 \%$ to $78 \%$, respectively, after SAVER. ${ }^{2,3}$ In the present study, the 5- and 10-year overall survival rates were $72.4 \%$ and $59.2 \%$, and the 5- and 10-year freedom from major adverse cardiac or cerebrovascular event rates were $73.8 \%$ and $61.2 \%$, respectively. Although a recent multicenter trial comparing CABG with and without surgical ventricular reconstruction (Surgical Treatment for Ischemic Heart Failure $[\mathrm{STICH}]$ trial) failed to demonstrate any advantages to adding surgical ventricular restoration to $\mathrm{CABG},{ }^{12}$ the flaws indicated in the STICH trial should be addressed; SAVER could be a valid surgical option to improve the clinical outcomes in patients with a failing ischemic heart. ${ }^{13,14}$ The present study has demonstrated that the LVESVI was reduced $40 \%$ in the early postoperative period when evaluated echocardiographically and $39 \%$ at 3 months postoperatively when evaluated using SPECT. This is in agreement with the suggestion of Suma and Anyanwu ${ }^{15}$ that most surgeons can achieve a volume reduction of $>30 \%$ after SAVER with appropriate training and good technique. In the STICH trial, however, the LVESVI was reduced only $19 \%$ at 4 months after surgery. ${ }^{12}$ 
Those findings also suggested that volume reduction surgery in the STICH trial might have been suboptimal, and the conclusions reached might have been misguided. ${ }^{13,15}$

Our operative strategy for ischemic cardiomyopathy during the study period was to perform SAVER concomitant with total arterial graft revascularization. Most patients with ischemic cardiomyopathy will have a mixture of stunned, hibernating, remodeled, and nonviable myocardium and will, therefore, show varying degrees and timing of functional improvement after revascularization depending on the preoperative ratios of these components. ${ }^{16,17}$ Because total arterial revascularization has demonstrated excellent graft patency rates and good clinical results, ${ }^{18,19}$ we have presumed that long-term maintenance of graft patency will be even more important for recovery of the dilated failing ischemic myocardium. In the present study, the overall and left coronary artery territory graft patency rates at 5 years postoperatively were $92.0 \%$ and $95.7 \%$, respectively. The preserved midterm patency of arterial grafts, particularly in the left coronary territory, might have an important role in maintaining improved LV function up to 5 years postoperatively.

\section{Study Limitations}

The present study had limitations that must be recognized. First, the present study was a retrospective observational study at a single institution, although all consecutive patients were enrolled. Second, follow-up echocardiography and myocardial SPECT were not performed in all patients. Although we adopted a generalized estimating equation to overcome this limitation, selection bias could have affected our results. Third, cardiac magnetic resonance imaging, which has been recognized as the reference standard for the assessment of ventricular volumes, was not performed in the early postoperative period of our study and cardiac magnetic resonance imaging data were not included. However, previous studies have demonstrated a good correlation in the measured volumes between magnetic resonance imaging and myocardial SPECT. ${ }^{20}$ Therefore, observation of the serial changes in the LV volumes measured using myocardial SPECT seemed to be sufficient. Finally, we did not compare our results with those of SAVER performed with CABG using $\geq 1$ vein grafts, because almost all SAVER operations at our institution were performed with total arterial revascularization during the study period.

We wish to thank the Medical Research Collaborating Center of Seoul National University Hospital for their efforts in statistical assistance.

\section{References}

1. Dor V, Saab M, Coste P, Kornaszewska M, Montiglio F. Left ventricular aneurysm: a new surgical approach. Thorac Cardiovasc Surg. 1989;37: $11-9$

2. Athanasuleas CL, Buckberg GD, Stanley AWH, Siler W, Dor V, Di Donato M, et al. Surgical ventricular restoration in the treatment of congestive heart failure due to post-infarction ventricular dilation. J Am Coll Cardiol. 2004;44: $1439-45$.

3. Sartipy U, Albage A, Lindblom D. Risk factors for mortality and hospital readmission after surgical ventricular restoration. Eur J Cardiothorac Surg. 2006;30:762-9.

4. Fujii H, Ohashi H, Tsutumi Y, Kawai T, Lino K, Onaka M. Radionuclide study of mid-term left ventricular function after endoventricular circular patch plasty. Eur J Cardiothorac Surg. 2004;26:125-8.

5. Menicanti L, Castelvecchio S, Ranucci M, Frigiola A, Santambrogio C, de Vincentiis C, et al. Surgical therapy for ischemic heart failure: single-center experience with surgical anterior ventricular restoration. J Thorac Cardiovasc Surg. 2007;134:433-41.

6. Dor V, Sabatier M, Montiglio F, Civaia F, Di Donato M. Endoventricular patch reconstruction of ischemic failing ventricle: a single center with 20 years' experience: advantages of magnetic resonance imaging assessment. Heart Fail Rev. 2004:9:269-86.

7. Germano G, Kiat H, Kavanagh PB, Moriel M, Mazzanti M, Su HT, et al. Automatic quantification of ejection fraction from gated myocardial perfusion SPECT. J Nucl Med. 1995;36:2138-47.

8. FitzGibbon GM, Burton JR, Leach AJ. Coronary bypass graft fate: angiographic grading of 1400 consecutive grafts early after operation and of 1132 after one year. Circulation. 1978;57:1070-4.

9. Ueno T, Sakata R, Iguro Y, Yamamoto H, Ueno M, Ueno T, et al. Mid-term changes of left ventricular geometry and function after Dor, SAVE and Overlapping procedures. Eur J Cardiothorac Surg. 2007;32:52-7.

10. Di Donato M, Fantini F, Toso A, Castelvecchio S, Menicanti L, Annest L, et al. Impact of surgical ventricular reconstruction on stroke volume in patients with ischemic cardiomyopathy. J Thorac Cardiovasc Surg. 2010; 140:1325-31.

11. Di Donato M, Fantini F, Menicanti L. Reply to the editor. J Thorac Cardiovasc Surg. 2011;141:1553-4.

12. Jones RH, Velazquez EJ, Michler RE, Sopko G, Oh JK, O’Connor CM, et al Coronary bypass surgery with or without surgical ventricular reconstruction. N Engl J Med. 2009;360:1705-17.

13. Buckberg GD, Athanasuleas CL. The STICH trial: misguided conclusions J Thorac Cardiovasc Surg. 2009;138:1060-4.

14. Dor V, Civaia F, Alexanderscu C, Sabatier M, Montiglio F. Favorable effects of left ventricular reconstruction in patients excluded from the surgical treatments for ischemic heart failure (STICH) trial. J Thorac Cardiovasc Surg. 2011;141: 905-16.

15. Suma H, Anyanwu AC. Current status of surgical ventricular restoration for ischemic cardiomyopathy. Semin Thorac Surg. 2012;24:294-301.

16. Shivalkar B, Maes A, Borgers M, Ausma J, Scheys I, Nuyts J, et al Only hibernating myocardium invariably shows early recovery after coronary revascularization. Circulation. 1996;94:308-15.

17. Narula J, Dawson MS, Singh BK, Amanullah A, Acio ER, Chaudhry FA, et al. Noninvasive characterization of stunned, hibernating, remodeled and nonviable myocardium in ischemic cardiomyopathy. J Am Coll Cardiol. 2000;36:1913-9.

18. Tavilla G, Kappetein AP, Braun J, Gopie J, Tjien ATJ, Dion RAE. Long-term follow-up of coronary artery bypass grafting in three-vessel disease using exclusively pedicled bilateral internal thoracic and right gastroepiploic arteries. Ann Thorac Surg. 2004:77:794-9.

19. Kamiya H, Watanabe G, Takemura H, Tomita S, Nagamine H, Kanamori T. Total arterial revascularization with composite skeletonized gastroepiploic artery graft in off-pump coronary artery bypass grafting. J Thorac Cardiovasc Surg. 2004; 127:1151-7.

20. Kondo C, Fukushima K, Kusakabe K. Measurement of left ventricular volumes and ejection fraction by quantitative gated SPECT, contrast ventriculography and magnetic resonance imaging: a meta-analysis. Eur J Med Mol Imaging. 2003;30: $851-8$. 